\title{
Regional Features of the Buoyancy Frequency Distribution in the Laptev and East Siberian Seas
}

\author{
A. A. Bukatov, E. A. Pavlenko*, N. M. Solovei \\ Marine Hydrophysical Institute of RAS, Sevastopol, Russian Federation \\ *mhi.pavlenko@gmail.com
}

\begin{abstract}
Purpose. The aim of the paper is to study buoyancy frequency in the Laptev and East Siberian Seas and to assess correlation relations between the intra-year variability of the Väisäl - Brent frequency maximum and the climatic indices reflecting the atmosphere and hydrosphere state.

Methods and Results. Based on the World Ocean Atlas 2013 for 1955-2012, the features of spatial and temporal variability of the buoyancy frequency distribution and its maximum depth in the Laptev and East Siberian seas are considered. It is found that the highest values of the Väisäl - Brent frequency are observed in the estuaries of the rivers Lena, Khatanga, Kolyma and Indigirka in summer where they attain 70-86 cycle/hour. In the deep-water northern areas of the seas under study, the majority of the water area is covered with ice throughout the whole year. As a consequence the surface layer of water is heated slightly and stability of stratification is much lower. The buoyancy frequency values in the seasonal pycnocline attain 24-46 cycle/hour. As a result of advection of the transformed Pacific waters in the northern and southeastern regions of the East Siberian Sea, on the depths $25-55 \mathrm{~m}$ observed is the layer of constant pycnocline where the Väisäl - Brent frequency values can mount to $21 \mathrm{cycles} /$ hour. Correlation analysis is carried out for the relations between the intra-annual variability of the Väisäl - Brent frequency maximum and the climatic indices (North Atlantic Oscillation, Arctic Oscillation, Pacific Decadal Oscillation, Gulf Stream North Wall) reflecting the atmosphere and hydrosphere state. It is shown that relationship between the buoyancy frequency maximum and the two latter indices is the most pronounced.

Conclusions. The results of the carried out investigations show that the features of spatial-temporal variability of the buoyancy frequency distribution and its maximum depth in the Laptev and East Siberian seas are conditioned by the river discharge and also by advection in the Arctic region of the Atlantic and transformed Pacific waters inflowing from the adjacent basins.
\end{abstract}

Keywords: Arctic, Laptev Sea, East Siberian Sea, buoyancy frequency, water stability, water vertical structure.

Acknowledgments: the research is carried out within the framework of the state order on theme No. 0827-2019-0003.

For citation: Bukatov, A.A, Pavlenko, E.A. and Solovei, N.M., 2019. Regional Features of the Buoyancy Frequency Distribution in the Laptev and East Siberian Seas. Physical Oceanography, [e-journal] 26(5), pp. 387-396. doi:10.22449/1573-160X-2019-5-387-396

DOI: $10.22449 / 1573-160 \mathrm{X}-2019-5-387-396$

(C) 2019, A. A. Bukatov, E. A. Pavlenko, N. M. Solovei

(C) 2019, Physical Oceanography

\section{Introduction}

Under the conditions of modern climatic variations in the Arctic, studies of the seasonal and interannual variability of the hydrological regime of the seas of the Arctic zone of the Russian Federation have acquired an increasing relevance. This is due to the presence of unique natural resources in this region, as well as to the prospects for the development of the transport capacity of the Northern Sea Route [1-2]. Many authors have addressed the analysis of the spatiotemporal variability of the hydrometeorological characteristics of the Arctic seas of Russia [3-10]. With an increase in the hydrological data availability, an improvement in the quality of measurements on expeditions and methods for their processing, it becomes 
possible to give a more reliable description of the state and climatic variability of the hydrological regime of the Arctic Seas. The sea water density is the most significant hydrological characteristics. Water stability is one of the main factors determining the depth of vertical convective mixing of water [11, 12]. The Väisäl Brent frequency (buoyancy frequency) is a parameter characterizing the vertical density stratification of waters.

The regional buoyancy frequency distribution in the Laptev and East Siberian Seas on a climatic scale is studied in the present paper. Estimates of the correlation between the intra-annual variability of the Väisäl - Brent frequency maximum and climatic indices reflecting the atmosphere and hydrosphere state are obtained.

\section{Materials and Methods}

As the initial data monthly mean climatic arrays of temperature and salinity from the World Ocean Atlas $2013[13,14]$ for $1955-2012$ at $0.25^{\circ} \times 0.25^{\circ}$ grids with $5 \mathrm{~m}$ step in depth to $100 \mathrm{~m}$ horizon and $25 \mathrm{~m}$ step to $150 \mathrm{~m}$ horizon were used. The study area is limited by $68^{\circ}$ and $81^{\circ} \mathrm{N}$ parallels and $95^{\circ}$ and $180^{\circ} \mathrm{E}$ meridians. Density was calculated from monthly average temperature and salinity values. The data obtained was tested for detecting inversions and, if necessary, was corrected by replacing the inversion values with those interpolated over adjoined horizons. For each grid node, monthly average climatic profiles of the Väisäl Brent frequency values ( $\mathrm{N}$, cycle/hour) were calculated using the following formula

$$
N^{2}(z)=\frac{g}{\rho} \frac{d \rho}{d z},
$$

where $z$ is the depth; $g$ is the free fall acceleration; $\rho$ is the density [15].

The maximum of the Väisäl - Brent frequency was determined from the depth $N_{\max }(z)$ and its occurrence depth $Z$. To characterize the spatio-temporal variability of water stability, the monthly average buoyancy frequency profiles were calculated for regions with different hydrological structures. Spatial averaging of the buoyancy frequency values was carried out at each horizon for the areas selected.

A correlation analysis was carried out between the intra-annual variability of the Väisäl - Brent frequency maximum and global climate indices: North Atlantic Oscillation (NAO), Arctic Oscillation (AO) (http://www.cpc.ncep.noaa.gov/), Pacific Decadal Oscillation (PDO) (http://jisao.washington.edu/pdo), as well as the position index of the Gulf Stream North Wall (GSNW) (http://www.pml-gulfstream.org).

\section{Analysis of the Results}

Hydrological conditions of the Laptev and East Siberian Seas are mainly determined by their geographic location (free movement with the Central Arctic basin), continental runoff and great ice coverage [3,4]. The total volume of continental runoff to the Laptev Sea is $30 \%$ of the total volume of continental runoff to all the Arctic seas of Russia. The runoff volume to the East Siberian Sea is much less - about $10 \%$ of the total runoff ${ }^{1}$.

${ }^{1}$ Dobrovol'skii, A.D. and Zalogin, B.S., 1982. [Seas of the USSR]. Moscow: MGU, $192 \mathrm{p}$. (in Russian). 
Based on a generalization of the features of the vertical density structure and geostrophic circulation, regions with different hydrological water structures were identified (Fig. 1): in the Laptev Sea - the southwestern $\left(73^{\circ}-76^{\circ} \mathrm{N}\right.$ and $109^{\circ}-$ $\left.125^{\circ} \mathrm{E}\right)$, the southeastern $\left(70^{\circ}-76^{\circ} \mathrm{N}\right.$ and $\left.125^{\circ}-143^{\circ} \mathrm{E}\right)$, the northern $\left(76^{\circ}-81^{\circ} \mathrm{N}\right.$ and $\left.100-143^{\circ} \mathrm{E}\right)$; in the East Siberian Sea - the southwestern $\left(69^{\circ}-76^{\circ} \mathrm{N}\right.$ and $143^{\circ}-$ $\left.165^{\circ} \mathrm{E}\right)$, the southeastern $\left(69^{\circ}-76^{\circ} \mathrm{N}\right.$ and $\left.165^{\circ}-180^{\circ} \mathrm{E}\right)$ and northern $\left(76^{\circ}-81^{\circ} \mathrm{N}\right.$ and $\left.143^{\circ}-180^{\circ} \mathrm{E}\right)$.

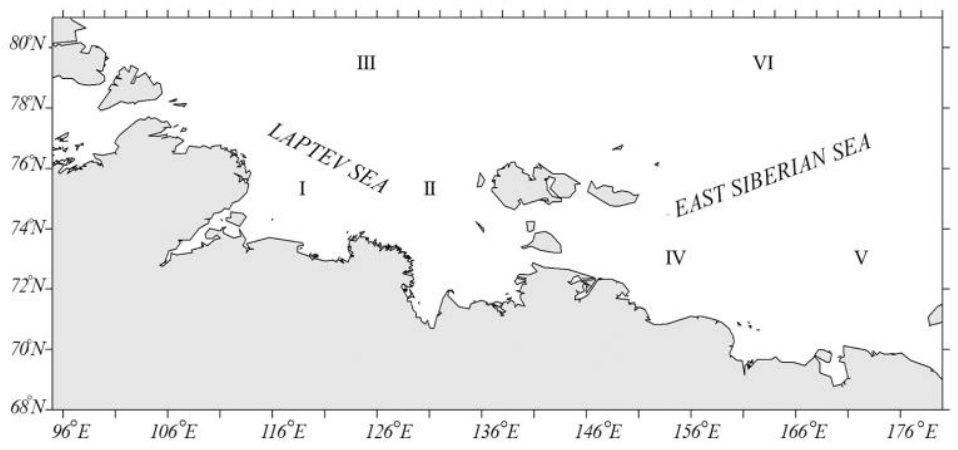

F i g. 1. Scheme of areas in the Laptev Sea: southwest (I), southeast (II), northern (III); in the East Siberian Sea: southwestern region (IV), southeastern (V) and northern (VI)

Greater part of the Laptev and East Siberian sea waters to 30-50 m depths is occupied by the surface Arctic water mass coming from the Arctic Ocean ${ }^{1}$. It is characterized by low temperature and low salinity. In zones of strong influence of coastal runoff (regions I, II and IV) as a result of mixing of river and surface Arctic waters, water with a relatively high temperature and low salinity is formed. At their interface (5-10 m horizon), large gradients of salinity and density are created. In the deeper northern regions (III, VI), there is a more saline and colder layer under surface Arctic waters. It is formed as a result of mixing of surface Arctic and deep Atlantic water masses [16]. Vertical structure of the northern and eastern parts of the East Siberian Sea is also formed under the influence of advection of transformed Pacific waters flowing through the Long Strait or along the northern coast of Wrangel Island from the Chukchi Sea. In ice-condition favorable years in regions V and VI, the transformed Pacific water mass, characterized by elevated temperatures and salinity, displaces Arctic waters and is located above the bottom water [17].
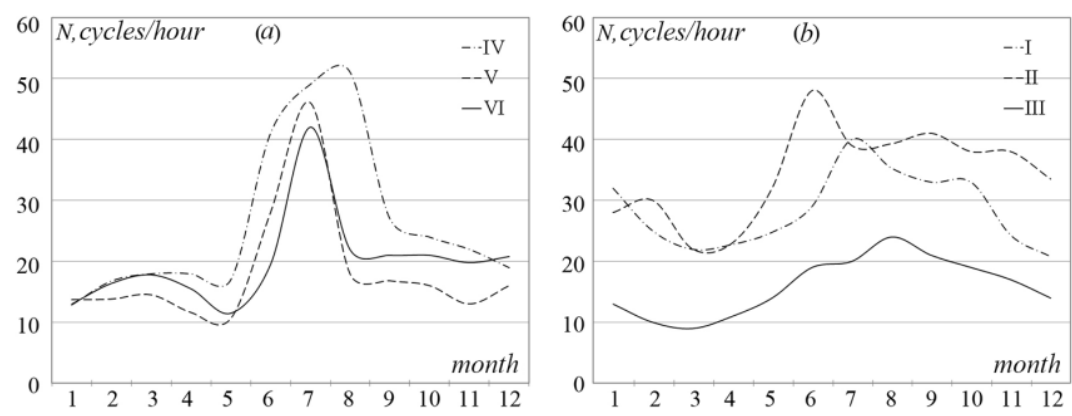

F i g. 2. Climatic intra-annual course of the maximum frequency of buoyancy in the East Siberian Sea $(a)$, the Laptev Sea $(b)$. Roman numerals denote areas of the seas 
Analysis of the climatic intra-annual course of the maximum buoyancy frequency in the Laptev and East Siberian seas (Fig. 2) showed that the maximum values of the buoyancy frequency are observed in June - August and the minimum ones - in March - May. Moreover, in the southern regions of the Laptev Sea, the maximum is in January - February. In the Laptev Sea, the annual variation range $N_{\max }(z)$ is 14-27 cycles/hour and in the East Siberian Sea - 30-36 cycles/hour.

Density water stratification starts to go up in late spring, when the upper layer of water is desalinated and warmed up due to ice melting and river runoff increase. Due to their low density, river waters spread over the surface of cold sea waters and can be traced at a considerable distance from the estuarine areas ${ }^{1}$. In the warm season, the density stratification is the highest in the southeastern and southwestern parts of the Laptev Sea (Fig. 2, $b ; 3,4)$. At the Lena River estuary, the values of $N_{\max }(z)$ reach 86 cycles/hour in July, at the Khatanga River estuary 75 cycles/hour (Fig. 5). In the southeastern Laptev Sea, where under the influence of cyclonic circulation in the surface sea layer, most of the Khatanga and Lena runoff is spread, a pycnocline is observed throughout the entire year. The maximum in the intra-annual cycle of water stability in the southeastern and southwestern regions of the Laptev Sea is observed in June $\left(N_{\max }(z)=48\right.$ cycle/hour) and July $\left(N_{\max }(z)=40\right.$ cycle/hour $)$ with a maximum depth of $5 \mathrm{~m}$ (Fig. 2, 6). Wind mixing in the ice-free spaces of the Laptev Sea in the summer is poorly developed, contributing to an increase in the density water stratification ${ }^{1}$.

In the deeper northern regions of the Laptev Sea during the warm season, stratification is much less than in the southern part of the sea. The greater northern part of the sea is covered with ice, and the surface layer of water is slightly warmed mean value of $N_{\max }(z)$ is 24 cycles/hour and $Z_{\max }=15 \mathrm{~m}$ (Fig. $2, b ; 6$ ).

In the East Siberian Sea, density stratification is most pronounced in the southwest of the sea, where desalinated coastal waters, as well as the waters of the Kolyma and Indigirka Rivers, flow through the Laptev and Sannikov Straits. In this area, the pycnocline can be traced from June to September, and by the end of the warm period of the year it is destroyed by wind mixing (Fig. 4). In the estuarine areas, $N_{\max }(z)$ values reach $70-85$ cycles/hour (Fig. 5). The intraannual maximum stability in the southwestern region of the East Siberian Sea falls in August. The mean $N_{\max }(z)$ value is 51 cycles/hour, while the maximum depth is $5 \mathrm{~m}$ (Fig. 2, $a$; 6).
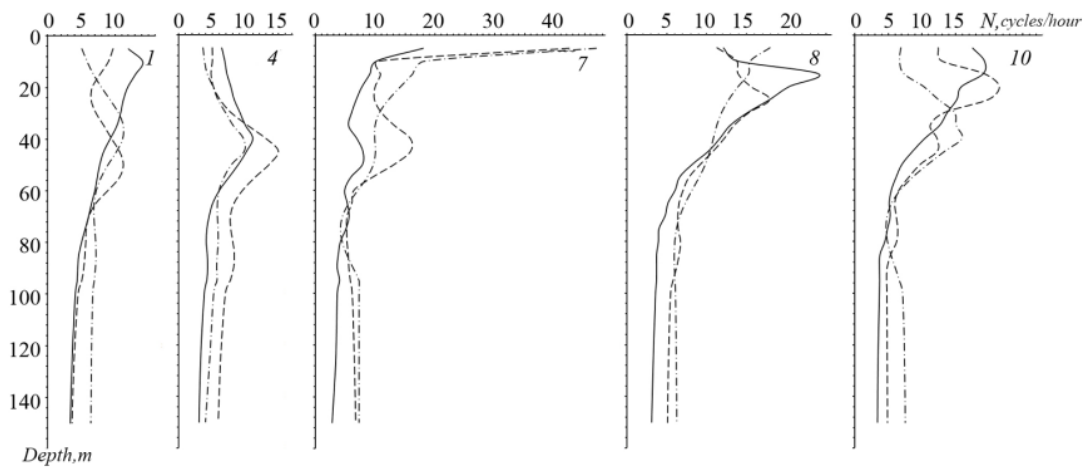

F i g. 3. Monthly average frequency profiles of buoyancy: III (-); VI (- - -), V (- - - -). The numbers in the picture indicate the months 


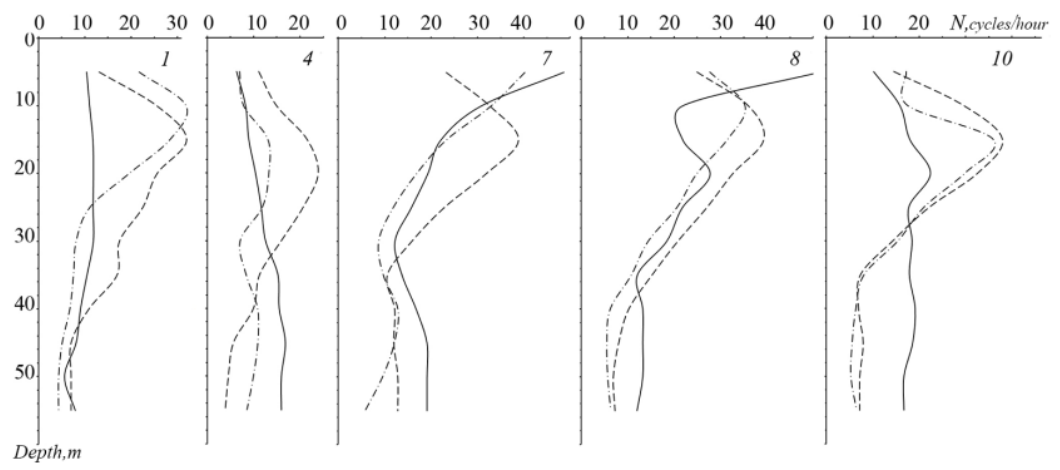

F i g. 4. Monthly average frequency profiles of buoyancy: IV ( - ), II (- - -), I (- - - - ). The numbers in the picture indicate the months

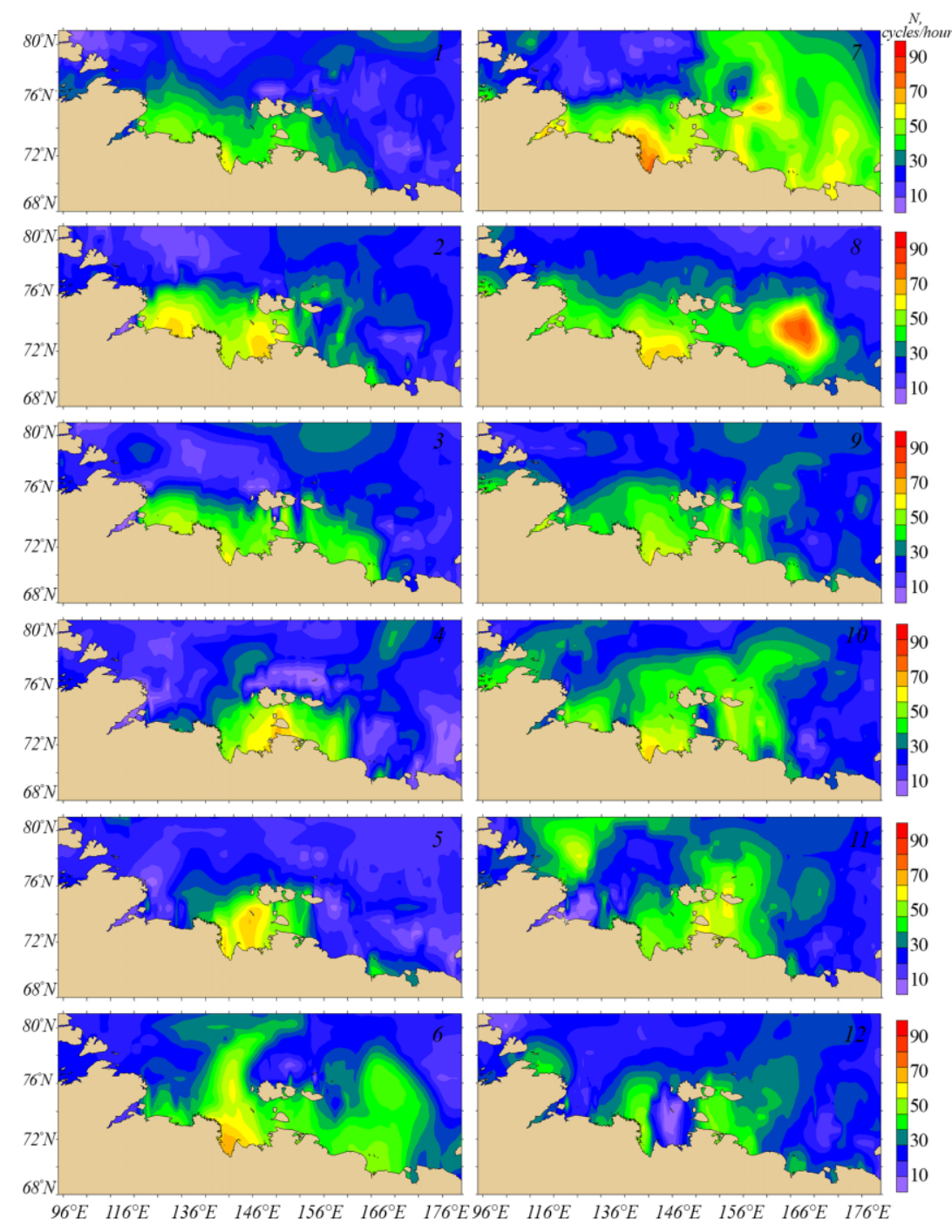

F i g. 5. Maps of the distribution of monthly average values of the maximum frequency of buoyancy in the Laptev Sea and the East Siberian Sea 
In the deeper sea parts $(\mathrm{V}, \mathrm{VI})$, the maximum of the intra-annual cycle of water stability falls on July (Fig. 2a): in the southeastern sea area (V), the mean $N_{\max }(z)$ value is 46 cycles/hour and in the northern one (VI) - 42 cycles/hour, for both regions $Z_{\max }=5 \mathrm{~m}$ (Fig. 2a; 6). Moreover, large density gradients in the southeastern and northern regions of the sea are observed throughout the year at 25-55 m depths (see Fig. 3). These depths correspond to a constant pycnocline layer separating bottom waters and surface Arctic or Pacific waters coming from the Chukchi Sea $[16,17] . N_{\max }(z)$ values in the southeastern and northern regions in the constant density jump layer reach 12 and 18 cycles/hour in the warm season, respectively.
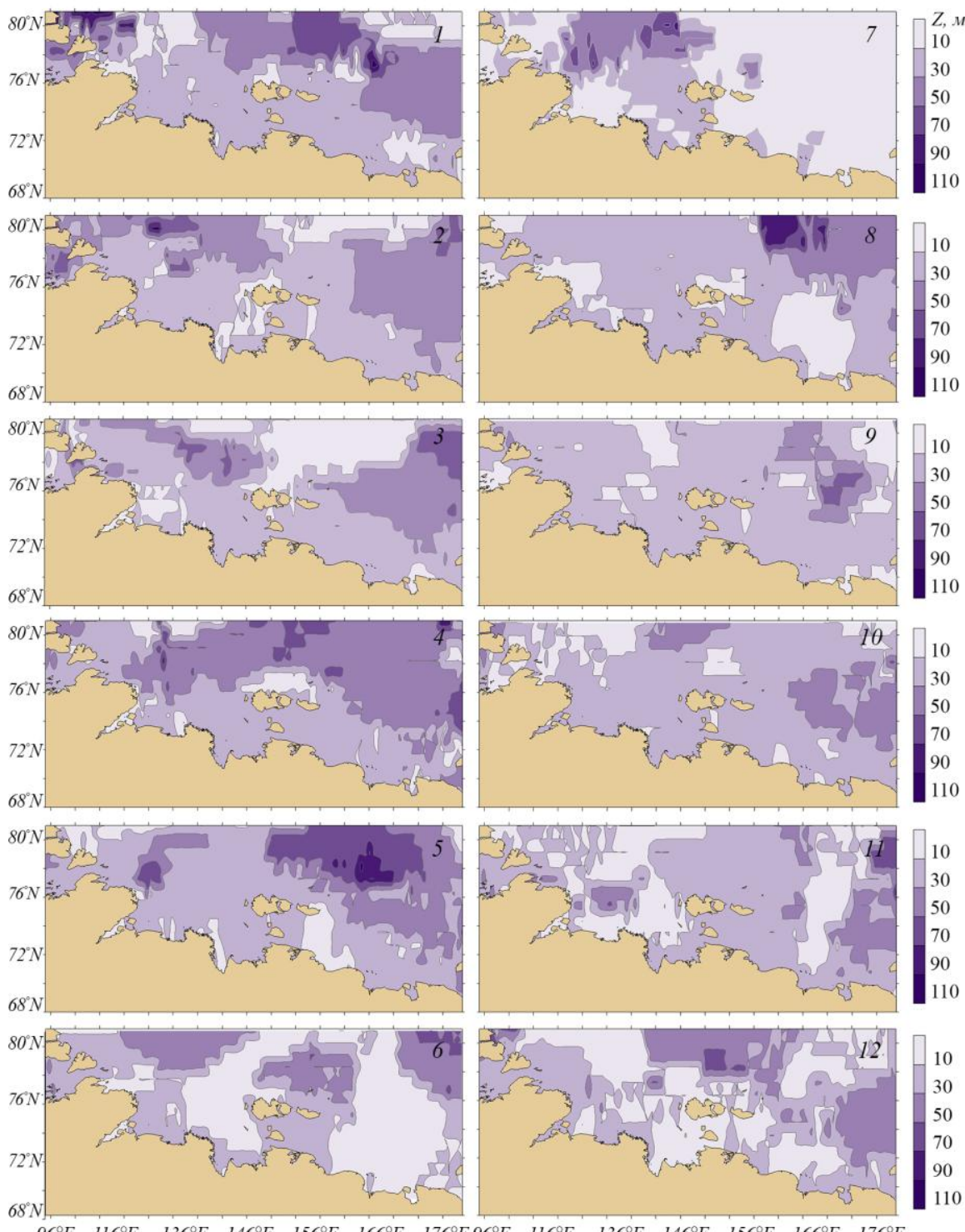

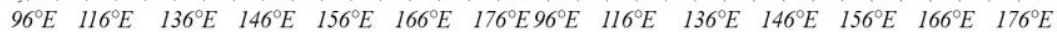

F i g. 6. Maps of the distribution of monthly average values of the depth of the maximum frequency of buoyancy in the Laptev Sea and the East Siberian Sea 
In October, river runoff decreases, ice formation begins, salinization and cooling of surface waters starts, and convection begins to develop. In the southern regions of the Laptev Sea, in the zone of Lena River runoff influence, river water spreads under the ice in the form of desalinated lenses ${ }^{1}$. Here, the pycnocline is observed throughout the entire cold season. At the same time, density stratification is maximal on the southeastern shelf of the sea.

In winter, in the Buor-Khaya Gulf $N_{\max }(z)$ values reach 73 cycles/hour. In winter, the density jump layer is at $10-15 \mathrm{~m}$ depths and in spring it deepens to $25 \mathrm{~m}$ (Fig. 5, 6).

By the end of the winter period, in the northern regions of the Laptev Sea, convective mixing extends to $100-150 \mathrm{~m}$ horizons. This is due to a small degree of water separation and the early start of ice formation, as well as the existence of shore ice edge polynya, open water areas or young forms of ice approximately corresponding to $20-25 \mathrm{~m}$ isobath [18].

In the southwestern region of the East Siberian Sea, autumn-winter convection penetrates to the bottom (40-45 m depths). In the deeper southeastern and northern regions, by the end of the cold season, the vertical circulation can extend to $55 \mathrm{~m}$ horizon, where it is limited by a stable density water structure. In these areas, the mean $N_{\max }(z)$ value in the constant pycnocline in the autumn-winter period is 21 cycles/hour (Fig. 3).

Correlation analysis between the intra-annual variability of the Väisäl - Brent frequency maximum and the NAO, AO, PDO and GSNW indices showed that the closest dependences are observed for the PDO and GSNW indices (Fig. 7).

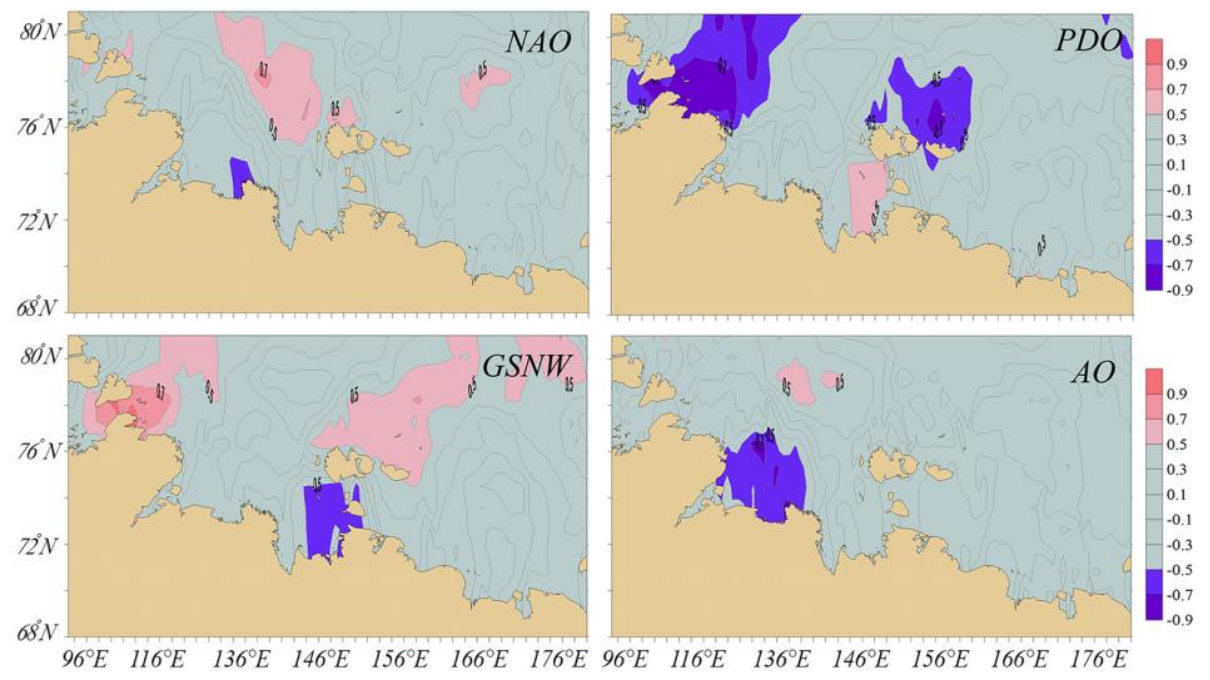

F i g. 7. Maps of the distribution of the values of the correlation coefficients between the values of the maximum frequency of buoyancy and climatic indices

The statistically significant ( $90 \%$ confidence interval) values of the correlation coefficients $(R)$ between $N_{\max }(\mathrm{z})$ and the PDO in the Laptev Sea north-west are within the range $-0.5 \ldots-0.9$. Between $N_{\max }(\mathrm{z})$ and GSNW in the northern and northwestern parts of the seas considered, correlation coefficients are from 0.5 to 0.9 .

PHYSICAL OCEANOGRAPHY VOL. 26 ISS. 5 (2019) 
The maximum correlation coefficients between $N_{\max }(z)$ and NAO values are fixed in the northern part of the Laptev Sea with $R$ equal to 0.8. Statistically significant correlation coefficients from -0.5 to -0.8 between $N_{\max }(z)$ and $\mathrm{AO}$ are observed in the southwestern region of the Laptev Sea (Fig. 7).

\section{Conclusion}

Based on the temperature and salinity World Ocean Atlas 2013 data, the research of the climatic features of the regional buoyancy frequency distribution in the Laptev and East Siberian Seas for 1955-2012 was carried out.

It was found that in the Laptev Sea, the intra-annual maximum of water stability is observed in the summer period with the highest density stratification in the estuaries of the Khatanga and Lena Rivers. In July $N_{\max }(z)$ values reach 86 cycles/hour in the Lena River estuary and 75 cycles/hour at the Khatanga River estuary. In the intra-annual cycle of water stability in the southeastern region of the sea, the maximum occurs in June, and in its southwestern part, in July, with mean $N_{\max }(z)$ values mounting to 48 and 40 cycles/hour for the indicated areas, respectively. The maximum depth in both cases is about $5 \mathrm{~m}$.

In the southern regions of the Laptev Sea, the pycnocline is observed throughout the year. In the warm season, it is close to the surface and in the cold one - at 10-15 m depths. In this case, $N_{\max }(z)$ values are maximum in the Buor-Khaya Gulf and on the southeastern shelf of the Laptev Sea and reach 73 cycles/hour in February. In the northern region of the sea, the intra-annual maximum of water stability was noted in August. Mean $N_{\max }(z)$ is 24 cycles/hour. The mean $N_{\max }(z)$ occurrence depth is $15 \mathrm{~m}$.

It is shown that in the East Siberian Sea, the intra-annual maximum of water stability for the northern and southeastern regions of the sea falls on July, and for the southwestern one - on August. Seasonal pycnocline is observed from June to September, its depth in all sea areas during the summer is $5 \mathrm{~m}$. Mean $N_{\max }(z)$ value in the southwestern region of the sea in August is 51 cycles/hour, in the northern and southeastern regions July - 46 and 42 cycles/hour, respectively. The maximum buoyancy frequency values are noted in the estuaries of the Kolyma and Indigirka Rivers. In these areas, $N_{\max }(z)$ values reach 70 and 85 cycles/hour. In the deep-water northern and southeastern regions of the East Siberian Sea, at 25-55 m depth, a layer of constant pycnocline, which can be traced throughout the year, is observed. Mean $N_{\max }(z)$ value in the jump layer reaches $12-18$ cycle/hour in the spring-summer period of the year and 21 cycle/hour in the autumn-winter one.

Correlation analysis between the intra-annual variability of the Väisäl - Brent frequency maximum and the NAO, AO, PDO and GSNW indices showed that the closest dependences are observed for the PDO and GSNW indices. Consequently, the inflow of warm Atlantic waters into the Arctic basin is one of the factors affecting the seasonal buoyancy frequency variation. The correlation coefficients between the maximum Väisäl - Brent frequency in depth and the GSNW position index lie in the range from 0.5 to 0.9 for the northern and northwestern regions of the seas under study.

Vertical density structure of the northern parts of the East Siberian Sea and the Laptev Sea is also formed under the influence of advection of transformed 
Pacific waters coming from the Chukchi Sea. The correlation coefficients between the maximum Väisäl - Brent frequency in depth and the PDO index in the northern regions reach $-0.5 \ldots-0.9$.

\section{REFERENCES}

1. Matishov, G.G., 2008. The Influence of Climatic and Ice Regime Variability on Navigation. Herald of the Russian Academy of Sciences, [e-journal] 78(5), pp. 457-463. https://doi.org/10.1134/S1019331608050043

2. Danilov, A.I., Alekseev, G.V. and Klepikov, A.V., 2014. The Consequences of Climate Change for Maritime Activity in the Arctic. Ice and Snow, 54(3), pp. 91-99. https://doi.org/10.15356/2076-6734-2014-3-91-99 (in Russian).

3. Borodachev, V.E. and Borodachev, I.V., 2016. Laptev Sea Ice Extent in Arctic Climate Fluctuation Conditions. Arctic and Antarctic Research, (3), pp. 60-73 (in Russian).

4. Bukatov, A.E., Bukatov, A.A. and Babiy, M.V., 2017. Spatial and Temporal Variability of the Arctic Sea Ice Distribution. Kriosfera Zemli, XXI(1), pp. 85-92. doi:10.21782/ KZ1560-7496-2017-1(85-92) (in Russian).

5. Bukatov, A.E., Pavlenko, E.A. and Solovei, N.M., 2017. [Variability of the Buoyancy Frequency Vertical Structure in the Arctic Seas of Russia]. In: S. O. Papkov, ed., 2017. Applied Problems of Mathematics: Materials of XXV International Scientific and Technical Conference (Sebastopol, September 18-22, 2017). Sevastopol: SevSU, pp. 65-67 (in Russian).

6. Bukatov, A.E. and Pavlenko, E.A., 2017. The Spatial and Temporal Variability of Distribution of the Buoyancy Frequency in the Chukchi Sea. Processes in GeoMedia, (3), pp. 573-579 (in Russian).

7. Golubeva, E.N., 2017. Numerical Modeling of the East-Siberian Sea Hydrology. In: SSUGT, 2017. Interexpo GEO-Siberia-2017. XIII International Scientific Congress: International Scientific Conference "Remote Sensing Methods of the Earth and Photogrammetry, Environmental Monitoring, Geoecology". Novosibirsk: SSUGT. Vol. 1, pp. 121-125 (in Russian).

8. Timokhov, L.A., Frolov, I.E., Kassens, H., Karpiy, V.Yu., Lebedev, N.V., Malinovsky, S.Yu., Polyakov, I.V. and Hoelemann, J., 2016. Changes of Termohaline Characteristics of Transpolar System of the Arctic Ocean. Arctic and Antarctic Research, (2), pp. 34-49 (in Russian).

9. Yurasov, G.I., 2000. [Oceanographic Characteristics of the Waters of the South-Eastern Part of the Laptev Sea and the Western Part (Dmitry Laptev Strait) of the East-Siberian Sea in September 1999]. In: I. P. Semiletov, ed., 2000. Proceedings of the Arctic Regional Centre. Vol. 2, part 1: Hydrometeorological and Biogeochemical Research in the Arctic. Vladivostok, pp. 63-68 (in Russian).

10. Bukatov, A.A., Pavlenko, E.A. and Solovei, N.M., 2018. [Spatio-Temporal Variability of the Buoyancy Frequency Distribution in the Laptev Sea and the East Siberian Sea]. In: MHI, 2018. The Seas of Russia: Seas of Russia: Methods, Means and Results of Research. Abstract Book of the All-Russian Scientific Conference (Sevastopol, 24-28 September, 2018). Sevastopol: MHI RAS, pp. 215-216 (in Russian).

11. Monin, A.S., Neyman, V.G. and Filyushkin, B.N., 1970. [Density Stratification in Ocean]. Doklady Akademii Nauk SSSR, 191(6), pp. 1277-1279 (in Russian).

12. Sherstyankin, P.P. and Kuimova, L.N., 2009. Vertical Stability and the Brunt-Väisäla Frequency of Deep Natural Waters by the Example of Lake Baikal, Lake Tanganyika, and the World Ocean. Doklady Earth Sciences, [e-journal] 429(2), pp. 1553-1558. https://doi.org/10.1134/S1028334X09090293

13. Locarnini, R.A., Mishonov, A.V., Antonov, J.I., Boyer, T.P., Garcia, H.E., Baranova, O.K., Zweng, M.M., Paver, C.R., Reagan, J.R., Johnson, D.R., Hamilton, M. and Seidov, D., 2013. World Ocean Atlas 2013, Volume 1: Temperature. NOAA Atlas NESDIS 73, 40 p. 
14. Zweng, M.M., Reagan, J.R., Antonov, J.I., Locarnini, R.A., Mishonov, A.V., Boyer, T.P., Garcia, H.E., Baranova, O.K., Johnson, D.R., Seidov, D., Biddle, M.M., 2013. World Ocean Atlas 2013, Volume 2: Salinity. NOAA Atlas NESDIS 74, 39 p.

15. Bukatov, A.E. and Solovei, N.M., 2017. Evaluation of the Density Field Vertical Structure and the Characteristics of Internal Waves Relation with Large-Scale Atmospheric Circulation in the Peruvian and Benguela Upwelling Areas. Processes in GeoMedia, (2), pp. 485-490 (in Russian).

16. Bloshkina, E.V., Makhotin, M.S., Volkov, D.L. and Koldunov, N.V., 2016. Comparison the Arctic Ocean the Thermohaline Characteristics Distribution from the Observed Data and MITgcm Model Simulated Data. Proceedings of the Russian State Hydrometeorological University, (43), pp. 67-88.

17. Makhotin, M.S. and Dmitrenko, I.A., 2011. Interannual Variability of Pacific Summer Waters in the Arctic Ocean. Doklady Earth Sciences, [e-journal] 438(1), pp. 730-732. https://doi.org/10.1134/S1028334X11050345

18. Morozov, E.G. and Pisarev, S.V., 2004. Internal Waves and Polynya Formation in the Laptev Sea. Doklady Earth Sciences, [e-journal] 398(7), pp. 983-986.

About authors:

Anton A. Bukatov - Senior Research Associate, Marine Hydrophysical Institute of RAS (2 Kapitanskaya Str., Sevastopol, 299011, Russian Federation), Ph.D. (Phys.-Math.), ORCID ID: 0000-0002-1165-8428, ResearcherID: P-6733-2017, newisland@list.ru

Ekaterina A. Pavlenko - Junior Research Associate, Marine Hydrophysical Institute of RAS (2 Kapitanskaya Str., Sevastopol, 299011, Russian Federation), ORCID ID: 0000-0001- 9146-5708, mhi.pavlenko@gmail.com

Nelya M. Solovei - Junior Research Associate, Marine Hydrophysical Institute of RAS (2 Kapitanskaya Str., Sevastopol, 299011, Russian Federation), ORCID ID: 0000-0003-3359-0345, ne.le.7@hotmail.com

Contribution of the co-authors:

Anton A. Bukatov - statement of the problem, analysis of the research data, analysis and revision of the text

Ekaterina A. Pavlenko - analysis and validation of results, preparation of graphic materials, preparation of the paper text

Nelya M. Solovei - development of the program algorithms, analysis of the results of numerical experiments, correction of the paper, reviewing the literature

All the authors have read and approved the final manuscript.

The authors declare that they have no conflict of interest. 